\title{
Barriers to Tracheostomy Weaning: A Case Report of Sialorrhea in a Patient with Persistent Seizure Activity and Head Injury
}

\author{
Hussain $Z^{1}$, Adshead $B^{2}$ and Thomas Amanda $\mathbf{J}^{3}$ \\ ${ }^{1}$ Senior Physiotherapist, the Royal London Hospital, Barts Health NHS Trust, London, United Kingdom. \\ ${ }^{2}$ Speech and Language Therapist, the Royal London Hospital, Barts Health NHS Trust, London, United Kingdom. \\ ${ }^{3}$ Clinical Specialist Physiotherapist, Critical Care Outreach Team, the Royal London Hospital, United Kingdom.
}

*Corresponding Author: Amanda Thomas, FCSP, Clinical Specialist Physiotherapist, Critical Care Outreach Team, the Royal London Hospital, United Kingdom.

\section{Received date: December 13, 2021; Accepted date: January 19, 2022; Published date: January 27, 2022}

Citation: Hussain Z, Adshead B and Thomas A.J. (2022). Barriers to Tracheostomy Weaning: A Case Report of Sialorrhea in a Patient with Persistent Seizure Activity and Head Injury. International Journal of Clinical Case Reports and Reviews. 10(4); DOI: 10.31579/2690-4861/197

Copyright: (C) 2022 Thomas Amanda J, This is an open access article distributed under the Creative Commons Attributiosn License, which permits unrestricted use, distribution, and reproduction in any medium, provided the original work is properly cited.

\begin{abstract}
:
We describe a single case following the acute hospital journey of a 54 year old admitted due to seizure activity and associated traumatic brain injury. The patient was cared for in a specialist neurosurgical centre. The hospital stay was complicated by difficulty managing seizure activity. The patient had several failed extubations due to high oral secretion burden, resulting in a percutaneous tracheostomy. Prolonged tracheostomy weaning ensued due to the impact of seizure activity, pharmacological interventions to manage both seizure activity and secretion management (including the use of Botulinum Toxin to the salivary glands), and dysphagia. Successful decannulation of tracheostomy was achieved 141 days after insertion and was associated with a reduction in antiepileptic drug administration.
\end{abstract}

Keywords: tracheostomy weaning; sialorrhea, hypersalivation; seizures; dysphagia; anti-epileptic drugs

\section{Glossary, Acronyms and Medical Abbreviations}

Computed Tomography (CT), One Way Valve (OWV), Anti-epileptic drugs (AED's), Nil By Mouth ( NBM), Electroencephalogram (EEG), Glasgow Coma Scale (GCS), Fibreoptic Endoscopic Evaluation of Swallowing (FEES), Pro re nata (PRN), Once a day (OD), Twice a day (BD), Three times a day (TDS), Four times a day (QDS), Arterio Venous Malformation (AVM), Sub Dural Haemorrhage (SDH), Fibreoptic Nasendoscopy (FNE), no abnormality detected (NAD), Magnetic Resonance Imaging (MRI), Central Nervous System (CNS), One Way Valve (OWV), Activities of Daily Living (ADL), Multi-Disciplinary Team (MDT), Hospital Acquired Pneumonia (HAP), Percutaneous Gastroscopy (PEG), Nasogastric Tube (NGT)

\section{Introduction}

Sialorrhea is defined as excessive saliva or hyper-salivation commonly associated with drooling. Some neurological conditions can cause autonomic changes leading to primary sialorrhea [1], and impairments in swallow which may affect oral secretion clearance [2]. Studies have also demonstrated hyper-salivation in patients who are post ictal $[3,4]$. The post-ictal presentation can also be associated with symptoms such as impaired consciousness, sensory and motor responses, hypersalivation and cognitive impairment [5].These symptoms have been shown to last from 3 seconds to 12.3 days [5]. There is a deficit of literature on the impact of excessive saliva production (or clearance) secondary to seizure activity on the tracheostomy weaning process.

Effective management of saliva permitting the removal of a tracheostomy can reduce the secondary complications of Tracheostomy insertion. Decannulation of tracheostomy restores physiological processes such as speech and swallow and may reduce the risk of aspiration, promote activities of daily living, progress physical rehabilitation, improve overall quality of life, facilitate hospital flow and reduce nursing/carer burden [6]. While management of sialorrhea with pharmaceutical agents such as anticholinergic drugs are often the first line approach, these have been associated with undesirable systemic effects due to inability to act specifically on salivary gland receptors (7). They have also been shown to affect the central nervous system, causing increased confusion, drowsiness and disorientation, which may be undesirable in the neurologically affected population [7]. Evidence demonstrates the efficacy of Botulinum Toxin for the management of excessive oral secretions with fewer systemic effects due to the direct effect on the salivary glands and longer duration of action $[1,2,8]$.

We present a single case of tracheostomy weaning which was excessively prolonged by the impact of seizure activity, pharmacological intervention to manage seizures, excessive oral secretion and dysphagia. 


\section{Background}

54 year old admitted following witnessed tonic-clonic seizure and a fall. CT demonstrated right tentorial SDH with subarachnoid extension to the quadrigeminal cistern and posterior quadrant. Cerebral angiogram was NAD. The SDH was conservatively managed. Past medical history included alcohol excess and outpatient investigation for six month history of left sided odynophagia, voice change and weight loss. Pre-admission FNE and MRI were largely normal. Seizures persisted during the first 3 days of admission despite medical management with Levetiracetam ( $2 \mathrm{~g}$ BD), Lacosamide (250mg BD), Lorazepam (1mg QD) and PRN Midazolam. On the $3^{\text {rd }}$ day the patient was transferred to critical care with on-going seizure activity and reduced GCS, requiring propofol and fentanyl sedation and intubation. Sodium Valproate was added to the AED's and ceftriaxone and acyclovir prescribed to cover possible CNS infection.

\section{Critical Care}

Ventilation requirements were minimal and a first trial of extubation occurred 4 days after critical care admission. This attempt failed due to high oral secretion load and on-going reduced GCS affecting airway protection. Two subsequent failed extubations in the following 5 days were due to an inability to manage oral secretions despite a trial of Hyoscine Hydrobromide. 11 days after critical care admission, a percutaneous tracheostomy with subglottic port was inserted. This step enabled liberation from mechanical ventilation and critical care discharge 5 days later.

\section{Tracheostomy Weaning}

Following critical care discharge, Hyoscine Hydrobromide was ceased in favour of Propantheline Bromide to help manage on-going high subglottic aspirates, oral and pulmonary secretions. Multiple AED's were prescribed to control seizure activity (Levetiracetam $2 \mathrm{~g}$ BD, Lacosamide 250mg BD, Sodium Valporate $1 \mathrm{~g}$ BD, Clonidine 25mg QDS, Lorazepam PRN). Tracheostomy weaning commenced 6 days after insertion and progressed to 24 hours cuff deflation and OWV tolerance on the 17th day after insertion. At this time the patient exhibited a GCS of 14, was mobile with therapist assistance, participating in ADL and had been started on thin fluids. High oral and chest secretion persisted despite demonstrating effective swallow and strong cough.

Unexpectedly, the patient then experienced multiple seizures and a reduced GCS. EEG findings were consistent with status epilepticus requiring increased dosages of Sodium Valproate and Lacusomide, and the introduction of Clobazam and Tropitramate when seizures were refractory. Tracheostomy weaning was suspended and an increased oral secretion burden required an increased dose of Propantheline Bromide. Over the next 3 weeks focal seizure activity reduced on serial EEG's but high oral secretion load persisted. Coupled with an ineffective swallow and drowsiness the patient was intolerant of short periods of cuff deflation and tracheostomy weaning was limited. At this stage, measured subglottic aspirates were in excess of $170 \mathrm{mls}$ over a 24 hour period (see Figure 1).

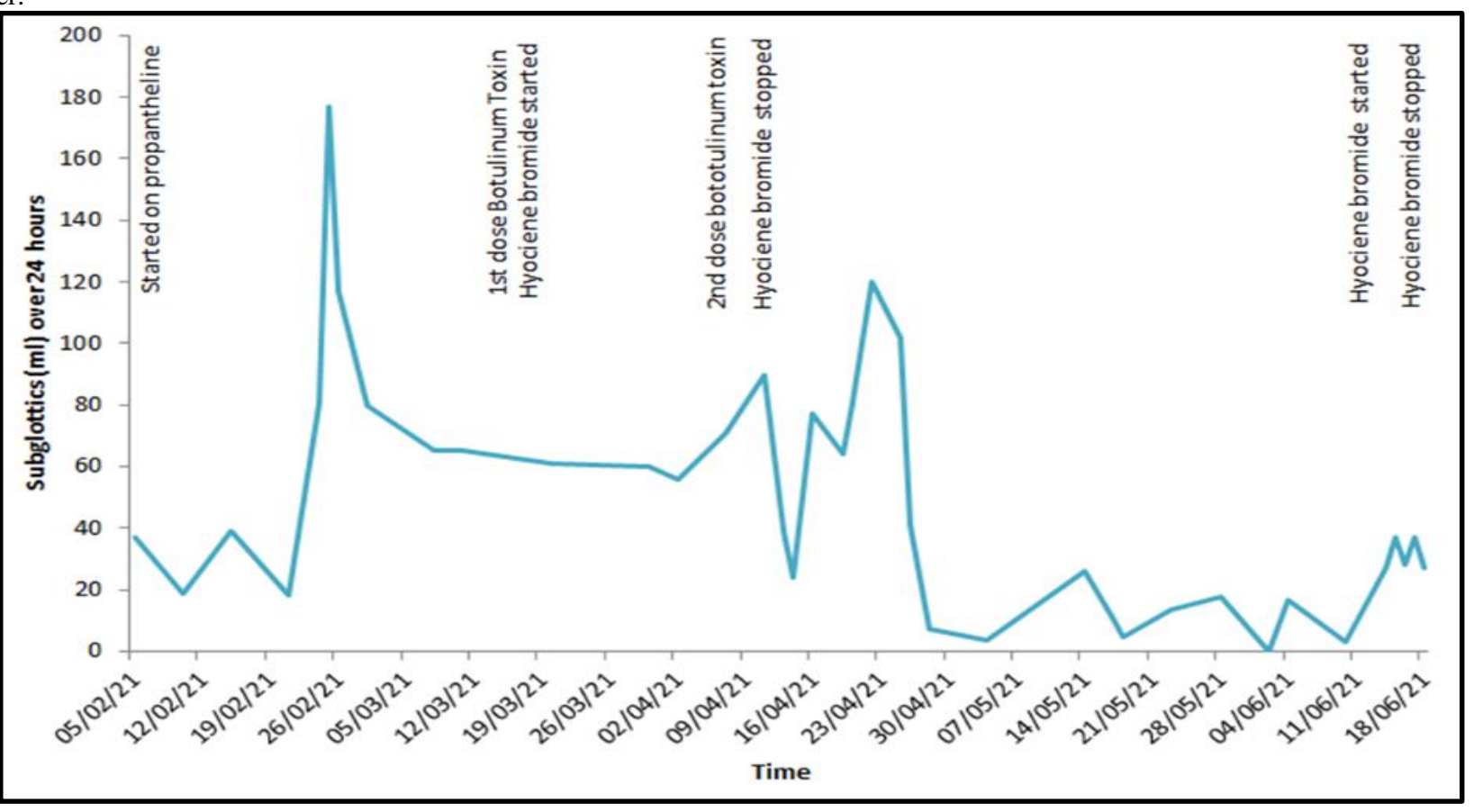

Figure 1: Daily Subglottic Secretion Volume Vs Time

46 days after tracheostomy insertion the MDT requested Botulinum Toxin to the bilateral submandibular glands, to reduce oral secretion and facilitate Tracheostomy weaning. Propantheline Bromide persisted (30mg TDS) but there was no significant change to oral secretion volume and after a further 14 days Hyociene Hydrobromide was recommenced (1.5mg patch). Tracheostomy weaning continued to be significantly limited by oral secretion load and prolonged coughing with cuff deflation. AED's were gradually weaned at this time including Topitramate, Clobazam, and Levetiracetam. There was no further seizure activity reported and the patient was able to follow single stage commands, with minimal verbal output.

60 days after tracheostomy insertion, FEES revealed severe motor and sensory dysphagia and a score of 7 on the New Zealand Secretion Scale (see first assessment Table 1). There was frank aspiration of thin fluids, puree diet and secretions. There was no cough response to aspiration, voluntary cough was ineffective. There was moderate-severe arytenoid oedema bilaterally with the right appearing slightly worse and an abnormality noted on the right vocal fold, thought to be due to repeated intubation oedema. 


\begin{tabular}{|c|c|c|c|c|}
\hline $\begin{array}{l}\text { The New Zealand } \\
\text { Secretion Scale }\end{array}$ & Symptom & $\begin{array}{l}\text { Score on } 1^{\text {st }} \\
\text { FEES }\end{array}$ & $\begin{array}{c}\text { Score on } 2^{\text {nd }} \\
\text { FEES }\end{array}$ & $\begin{array}{c}\text { Score on } 3^{\text {rd }} \\
\text { FEES }\end{array}$ \\
\hline Location & $\begin{array}{l}\text { Nil significant pooled secretions in pyriforms or laryngeal } \\
\text { vestibule }=0 \\
\text { Secretions in pyriform fossa }=1 \\
\text { Secretions in laryngeal vestibule }=2\end{array}$ & 2 & 2 & 1 \\
\hline Amount & $\begin{array}{c}\text { Nil significant pooled secretions in pyriform fossa }(0-20 \%)= \\
0 \\
\text { Secretions in pyriform fossa, not yet full }(20-80 \%)=1 \\
\text { Secretions filling }(80-100 \%) \text { or over spilling } \\
\text { pyriforms/interarytenoid space }=2\end{array}$ & 2 & 1 & 0 \\
\hline Response & $\begin{array}{l}\text { Secretions in pyriform fossa or laryngeal vestibule effectively } \\
\text { cleared }=0\end{array}$ & 3 & 3 & 0 \\
\hline & TOTAL SCORE & 7 & 6 & 1 \\
\hline
\end{tabular}

Table 1: The New Zealand Secretion Scale [27] scores across 3 FEES (Functional Endoscopic Evaluation of Swallow) assessments.

67 days post tracheostomy insertion, the patient had a second injection of Botulinum Toxin, on this occasion both submandibular and parotid glands were injected bilaterally. 21 days following these injections there was a dramatic decrease in measured subglottic aspirates (to $7.5 \mathrm{ml}$ over 24 hours, see Figure 1) but the patient remained highly productive of pulmonary secretions and tracheostomy weaning remained limited. AED's continued to be adjusted with increased doses of Levetiracetam and Clobazam.

88 days post tracheostomy insertion, cuff deflation had progressed to 1 hour twice a day. Bedside swallow assessment revealed improved tolerance to thin fluids with no overt signs of aspiration. Videofluoroscopy was unable to be completed due to lack of patient alertness for the procedure, but repeat FEES revealed a reduction in the volume of secretions penetrating the laryngeal vestibule with all consistencies trialled (see second assessment, Table 1).

100 days post tracheostomy insertion, the patient had progressed to 12 hours cuff deflation with OWV tolerance, but respiratory deterioration temporarily suspended weaning progress. Transient motor seizures accompanied this HAP required further adjustments to prescribed AED's (Levetiracetam, 2g BD, Sodium Valoprate, 1.3g BD, Clobazam, 20mg BD, Lacosamide, 300mg BD).

107 days post tracheostomy insertion the patient showed improvements in alertness and engagement, responding to questions and following single stage commands. Cuff deflation remained at 15 minute tolerance due to prolonged coughing, reduced swallow frequency and anterior loss of secretions (drooling) although measured subglottic aspirates remained minimal over a 24 hour period.

130 days post tracheostomy insertion, the patient had a failed PEG insertion due to iatrogenic bowel perforation and was made NBM, preventing administration of NGT Clobazam. Subsequently a 55 minutes seizure occurred requiring the addition of Phenytoin. Pulmonary secretions remained high, though measured subglottic aspirates had not been significant and all drying agents were stopped. No Tracheostomy weaning occurred during this period.
141 days post insertion tracheostomy weaning was recommenced, and quickly progressed to 12 hours cuff deflation during daylight hours with OWV tolerance. Repeat FEES 148 days post tracheostomy insertion (see third assessment, Table 1) showed significantly improved secretion management, nil aspiration or penetration and the patient was recommended to commence thin fluids and easy chew diet. Seizure activity was well controlled with AED's weaned to a therapeutic dose: Levetiracetam $2 \mathrm{~g}$ BD, Sodium valproate $1.3 \mathrm{~g}$ BD, Lacusomide $300 \mathrm{mg}$ BD with continuation of Escitalopram $15 \mathrm{mg}$ OD for mood. Tracheostomy weaning, alertness and engagement continued to progress and 159 days post tracheostomy insertion the tracheostomy was replaced with a mini-tracheostomy to accommodate ongoing pulmonary secretion requirements. The mini-tracheostomy was removed 6 days later.

\section{Discussion}

Challenges with oral secretion management can be a barrier to tracheostomy weaning and decannulation. In our case, tracheostomy weaning was limited by high volumes of oral and chest secretion evidenced by frequent coughing of secretions from the tracheostomy and frequent tracheal suctioning requirements. Conservative management of sialorrhea usually includes MDT input for erect posture maintenance, mobilisation, swallow rehabilitation and biofeedback [6]. In our case, use of these approaches was limited by the patient's reduced GCS, therefore pharmaceutical agents were considered. There is limited evidence for the use of drying agents during the acute management of patients with acquired brain injury. The use of these medications is derived from research describing their use in other populations such as Cerebral Palsy, Parkinson's disease, Motor Neurone Disease and Palliative Care.

The accepted pharmaceutical management of Sialorrhea are anticholinergic drugs due to their ability to bind to muscarinic receptors. Anticholinergic drugs are also favoured due to ease of availability and administration. However, anticholinergic drugs may cause undesirable systemic parasympathetic effects, such as; cardiac arrhythmias, constipation, headaches, blurred vision, urinary retention and drowsiness (Table 2) [7]. Some anticholinergic drugs such as glycopyrronium and propantheline show a reduced affinity to cross the blood brain barrier and are often the agent of choice in the neurological cohort [9]. In cases where 
use of anticholinergic drugs have been shown to be ineffective or unsuitable due to side effects, the administration of Botulinum toxin should be considered $[1,6]$.

Table 2: Comparison of drying agents and use of botox for Sialorrhea.

\begin{tabular}{|c|c|c|c|c|}
\hline Agent & Route of administration & $\begin{array}{c}\text { Dose and demonstrated } \\
\text { effectiveness }\end{array}$ & $\begin{array}{c}\text { Studied population for use in } \\
\text { Sialorrhoea }\end{array}$ & Common side effects \\
\hline $\begin{array}{l}\text { Botulimin Toxin A } \\
\text { (Xeomin) }\end{array}$ & $\begin{array}{l}\text { Injection directly into salivary } \\
\text { glands under ultrasoud guidace }\end{array}$ & $\begin{array}{l}\text { Recommended } 100 \text { units, parotid } \\
\text { glands: } 30 \text { units per side, } 0.6 \text { ml per } \\
\text { injection. submandibular glands: } 20 \\
\text { units per side, } 0.4 \text { ml per injection. } \\
\text { Maximal effect achieved at 2-3 } \\
\text { weeks. } \\
\text { Repeat doses not recommended } \\
\text { closer than } 16 \text { weeks. }\end{array}$ & $\begin{array}{l}\text { Parkinsons Disease } \\
\text { Motor Neurone Disease } \\
\text { Amytophic LateralSclerosis }\end{array}$ & $\begin{array}{l}\text { May need artificial saliva as can } \\
\text { casue excessively dry mouth. } \\
\text { May effect bulbar muscles causing } \\
\text { dysphagia. } \\
\text { Facialdrooping } \\
\text { Allergic reaction } \\
{[10,11,12]}\end{array}$ \\
\hline Glyopyrronium Bromide & $\begin{array}{l}\text { Subcutaneous injection, tablets or } \\
\text { oral solution/suspension }\end{array}$ & $\begin{array}{l}\text { Recommended stating dose: } 300- \\
600 \mathrm{mcg} / 24 \text { hours increasing to max } \\
1.2-1.6 \mathrm{mg} \text { day. } \\
\text { Has poor/ unpredictable asorption } \\
\text { when provised orally. } \\
\text { Slower onset of action- half life } \\
\text { approx. } 3 \text { hours. }\end{array}$ & $\begin{array}{l}\text { young people with } \\
\text { neurological disease eg. } \\
\text { Cerebral Palsy } \\
\text { Parkinsons Disease } \\
\text { schizophrenia and clozapine- } \\
\text { induced hypersalivation }\end{array}$ & $\begin{array}{l}\text { Cause dry mouth, vomiting, } \\
\text { constipation, Diarrhoea and nasal } \\
\text { congestion, flushing, some } \\
\text { behavioural cahnges. } \\
\text { To note: shown to be less permeable } \\
\text { to the blood brain barrier due to its } \\
\text { quatanery aliminuim structure. } \\
{[9,13]}\end{array}$ \\
\hline Hyocine Bromide & $\begin{array}{l}\text { Most commonly provided as a } \\
\text { transdermal patch, can also be } \\
\text { given in tablet form or injection. }\end{array}$ & $\begin{array}{l}\text { Recommended Patch: } 1 \mathrm{mg} / 72 \\
\text { hours } \\
\text { Tablets: } 150-300 \text { mcg upto BD } \\
\\
\text { Palliaitve care use: } \\
\text { By subcutaneous injection: } \\
400 \text { mcgs, } 4 \text { hours as required } \\
\text { By continuous subcutaneous } \\
\text { infusion: } 1.2-2 \mathrm{mg} / 24 \text { hours. }\end{array}$ & $\begin{array}{l}\text { Palliative care therapy } \\
\text { Clozipine induced } \\
\text { hypersalivation }\end{array}$ & $\begin{array}{l}\text { Skin irritation, eye disorders,impaired } \\
\text { concentration, hallucinations; } \\
\text { memory loss, restlessness, seizures, } \\
\text { bradycardia shw to be more } \\
\text { common than tachyardia. } \\
{[11,14]}\end{array}$ \\
\hline Propantheline Bromide & Tablet orally or via NG & Recommended $15-30 \mathrm{mgs}$ upto QDS & $\begin{array}{l}\text { clozapine induced } \\
\text { hypersalivation } \\
\text { Limited study in Neuro cohort- } \\
\text { some use in Amytrophic lateral } \\
\text { Sclerosis }\end{array}$ & $\begin{array}{l}\text { Common antimuscarinic side effects } \\
\text { include constipation, blurred vision, } \\
\text { urinary retention and drowsiness } \\
\text { To note: shown to be less permeable } \\
\text { to the blood brain barrier due to its } \\
\text { quatanery aliminuim structure. } \\
{[13,15]}\end{array}$ \\
\hline Atropine & Sublingual eye drops & $\begin{array}{l}\text { Recommended 1-2 drops upto 4- } 6 \\
\text { times daily }\end{array}$ & $\begin{array}{l}\text { Parkinsons Disease } \\
\text { clozapine induced } \\
\text { hypersalivation } \\
\text { Palliative care }\end{array}$ & $\begin{array}{l}\text { Poorly studied. Demonstratesthe } \\
\text { greatest risk of cardiac side effects. } \\
\text { Can reduce mucocilary transport } \\
\text { clearance. } \\
\text { Difficult to administer in those with } \\
\text { excessive drooling. } \\
\text { Psychotic disrder, Abdominal } \\
\text { distension, anhidrosis,anxiety, } \\
\text { bronchial secretions, dysphagia; } \\
\text { gastrointestinal disorders, } \\
\text { hallucination, movement } \\
\text { disorders,mydriasis, speech disorder, } \\
\text { loss of taste. } \\
{[11 b, 13,16,17]}\end{array}$ \\
\hline
\end{tabular}


Botulinum Toxin is a neurotoxic protein produced by the bacterium clostridium botulinum. It has been used since the 1970's for the therapeutic management of conditions such as dystonia, spasticity, strabismus and eye spasms. It has shown to have good efficacy on hypersalivation when administered directly to the salivary glands [2, 6]. Botulinum prevents the release of the neurotransmitter acetylcholine at the neuromuscular junction causing irreversible functional denervation which may last until the growth of new synapses [8]. Saliva production is mediated by parasympathetic nervous system control of three major paired salivary glands, two parotid, two submandibular and two sublingual. Research suggests the highest efficacy of secretion reduction is targeted Botulinum to the parotid and submandibular glands bilaterally [1] with the parotid glands receiving a higher dosage [18]. Botulinum can last an average of 3-6 months when administered under ultrasound guidance $[19,20]$. There is evidence in some populations that drooling scores do not return to baseline for 12 months following Botulinum injection [20].

Our case demonstrated significant improvement in saliva production as evidenced by the reduction in daily subglottic aspirate volume 3 weeks after the second round of Botulinum was administered (see Figure 1). The second administration targeted both parotid and submandibular glands in comparison to the first round, when only the submandibular glands were injected. Evidence suggests the maximum response to Botulinum is achieved 2-4 weeks after administration [20, 21]. Reduced saliva production in our case was correlated with progression of the tracheostomy wean but final progression toward decannulation readiness continued to be limited by the patients reduced cognitive function, engagement and reliance on high doses of AED's for the management of seizures. AEDs have been known to affect salivary gland function and can cause both sialorrhea and salivary gland hypofunction [22].

Typically, patients compensate for increased secretions through an increased frequency of swallow. In our case dysphagia impacted the ability to do this effectively. There were multiple factors which may have contributed to dysphagia, including; presence of an acquired brain injury, reduced GCS related to seizure activity, poly-pharmacy for seizure management, decompensation from a period of prolonged intubation and a prolonged period of NBM. Medications that depress the central nervous system such as AEDs (Sodium Valproate and Lorazepam) and Benzodiazepines can negatively impact swallow causing reduced awareness, reduced voluntary muscle control and difficulty initiating a swallow [23]. Dysphagia has been a noted side effect in $20 \%$ of patients on either single or multiple AEDs [24]. Dysphagia can manifest itself in terms of movement disorders, myopathy and salivary changes [25]. In addition to causing increased drowsiness, benzodiazepines may induce or exacerbate pharyngeal dysphagia by suppressing brainstem swallowing regulation [25]. In the case presented here, improved swallow function appeared in conjunction with therapeutic weaning of AED's. While it is difficult to attribute a single cause for successful tracheostomy weaning in the case presented, improved seizure status, reduction of secretion volume (with Botulinum toxin) and improved swallow following the reduction in AED's combined to allow the Tracheostomy to be removed.

\section{Conclusion}

Tracheostomy presence has been associated with significant impacts on quality of life $[2,26]$ and patient flow through a rehabilitation pathway. The MDT management of tracheostomy therefore focuses on the goal of successful decannulation. There are a number of criteria that must be fulfilled prior to considering decannulation, including prolonged tolerance to cuff deflation, and management of oral secretion load through functional swallow. In the case presented, secretion management and coughing associated with salivary aspiration significantly impacted the ability to progress the tracheostomy wean. Both oral secretion volume and dysphagia appear to have been negatively impacted by the use of multiple AED's to manage seizure activity. These drugs also impacted on the patients level of alertness and ability to engage consistently in rehabilitation sessions (sitting out of bed and mobilisation). In the case presented, pharmacological management of excessive oral secretion using Botulinum toxin and improved dysphagia coincident with the reduction of AED's appeared to remove the barriers preventing decannulation.

\section{References}

1. Restivo D. A, Panebianco M, Casabona A, Lanza S, MarcheseRagona R, Patti F, Masiero, S, Biondi A, Quartarone A. (2018). Botulinum Toxin A for Sialorrhoea Associated with Neurological Disorders: Evaluation of the Relationship between Effect of Treatment and the Number of Glands Treated. Toxins (Basel). 10(2):55.

2. Checklin M, Etty-Leal M, Iseli T.A, Potter N, Fisher S and Chapman L. (2015). Saliva management options for difficult-towean people with tracheostomy following severe acquired brain injury (ABI): A review of the literature. Brain Injury. 29(1):1-10.

3. Shah J, Zhai H, Fuerst D, Watson C. (2006). Hyper-salivation in Temporal Lobe Epilepsy. Epilepsia. 47(3):644-651.

4. Mader E.C, Xiang X.M, Olejniczak P.W, Miller D. (2021). Ictal Hypersalivation and Salivary Gland Enlargement in a Patient with Acquired Frontal Lobe Epilepsy. Cureus. 13(5):15319.

5. Subota A, Khan S, Colin B, Josephson B, Manjid S, Lukmanji S, Roach P, Wiebe S, Buchhalter J, Federico P, Campbell G, Teskey D, Lorenzetti D.L and Jetté N. (2019). Signs and symptoms of the postictal period in epilepsy: A systematic review and meta-analysis Epilepsy Behav. 94:243-251.

6. Hockstein N.G, Samadi D.S, Gendron K. (2004). Sialorrhea: a management challenge. American Family Physician. 69 (11):2628.

7. Prommer E. (2013) Anticholinergics in palliative medicine: an update. Am J Hosp Palliative Care. 30(5):490.

8. Mahant N, Clouston P.D, Lorentz I.T. (2000). The current use of botulinum toxin. J Clinical Neurosciences. 7(5):389-94.

9. NICE. (July 2013) Hypersalivation: oral glycopyrronium bromide. Evidence summary.

10. Banfi P, Ticozzi N, Lax A, Guidugli GA, Nicolini A, Silani V. (2015). A review of options for treating sialorrhea in amyotrophic lateral sclerosis. Respir Care. 60(3):446-454.

11. Mc Geachan, A.J. and Mcdermott, C.J. (2017). Management of oral secretions in neurological disease. Practical Neurology. 17(2):96-103.

12. NICE. (2019). Xeomin (botulinum neurotoxin type A) for treating chronic sialorrhoea.

13. McGeachan A.J, Hobson E.V, Al-Chalabi A. et al. (2016). A multicentre evaluation of oropharyngeal secretion management practices in amyotrophic lateral sclerosis. Amyotroph Lateral Scler Frontotemporal Degener.

14. NICE. (2017). Parkinson's disease in adults [NG71].

15. Breheret R, Bizon A, Jeufroy C, Laccourreye L. (2011). Ultrasound-guided botulinum toxin injections for treatment of drooling. European Ann Otorhinolaryngol Head Neck Dis. 128(5):224-229.

16. Khan W.U, Campisi P, Nadarajah S. (2011) Botulinum Toxin A for Treatment of Sialorrhea in Children: An Effective, Minimally Invasive Approach. Arch Otolaryngol Head Neck Surg. 137(4):339-344.

17. Reid S, Johnstone B, Westbury C, Rawicki B, Reddihough D. (2008). Randomized trial of botulinum toxin injections into the salivary glands to reduce drooling in children with neurological disorders. Dev Med Child Neurol. 50(2):123-128. 
18. Jongerius P. H, Frank J.A. Hoogen V.D, Limbeek J. V, Fons J, Gabreëls K, Van Hulst, J. and Rottevee, J. (2014). Effect of Botulinum Toxin in the Treatment of Drooling: A Controlled Clinical Trial. (2014) Pediatrics. 114 (3):620-627.

19. Miranda-Rius J, Brunet-Llobet L, Lahor-Soler E, Farré M. (2015). Salivary Secretory Disorders, Inducing Drugs, and Clinical Management. Int J Med Sci. 22. 12(10):811-824.

20. Balzer, K.M. (2000). Drug-Induced Dysphagia. Int J MS. 2 (1):4050.

21. Jahromi S.R, Togha M, Fesharaki S.H, Najafi M, Moghadam N.B, Kheradmand J.A, Kazemi H and Gorji A. (2011). Gastrointestinal adverse effects of antiepileptic drugs in intractable epileptic patients. Seizure. 20(4):343-346.

22. Buchholz D.W. (1995). Oropharyngeal dysphagia due to iatrogenic neurological dysfunction, Dysphagia. 10:248-254.

23. Gilony D, Gilboa D, Blumstein T, Murad H, Talmi Y.P, Kronenberg J, Wolf M. (2005) Effects of tracheostomy on wellbeing and body-image perceptions. Otolaryngol Head Neck. 133(3):366-371.

24. Miles A, Hunting A. (2018). Development, intra- and inter-rater reliability of the New Zealand Secretion Scale (NZSS). Int J Sp Lang Path.
This work is licensed under Creative Commons Attribution 4.0 License

To Submit Your Article Click Here:

Submit Manuscript

DOI: $10.31579 / 2690-4861 / 197$
Ready to submit your research? Choose Auctores and benefit from:

$>$ fast, convenient online submission

$>$ rigorous peer review by experienced research in your field

$>$ rapid publication on acceptance

$>$ authors retain copyrights

$>$ unique DOI for all articles

$>$ immediate, unrestricted online access

At Auctores, research is always in progress.

Learn more https://auctoresonline.org/journals/international-journal-of-clinicalcase-reports-and-reviews 